Pages: 36

Words: 3,425

Tables: 7

Figures: 2

References: 43

Contact: Marcus K. Taylor

E-mail: marcus.k.taylor2.civ@mail.mil

\title{
Anabolic Hormone Profiles in Elite Military Men
}

Marcus K. Taylor, PhD ${ }^{*}$; Shiloah A. Kviatkovsky, MS* Lisa M. Hernández, MS ${ }^{* \dagger}$;

Paul Sargent, MD (CDR, MC, USN) ${ }^{\S}$; Sabrina Segal, PhD ${ }^{\ddagger}$ Douglas A. Granger, PhD

*Biobehavioral Sciences Lab, Warfighter Performance Department, Naval Health Research

Center, 140 Sylvester Road, San Diego, CA 92106-3521.

${ }^{\dagger}$ Department of Exercise and Nutritional Sciences, San Diego State University, ENS Building,

Room 351, 5500 Campanile Drive, San Diego, CA 92182.

${ }^{+}$Institute for Interdisciplinary Salivary Bioscience Research, Arizona State University, 550 E.

Orange Street, Tempe, AZ 85287.

${ }^{\S}$ Naval Special Warfare Group ONE, 3632 Guadalcanal Road, Building 165, San Diego, CA

92155.

"Johns Hopkins School of Nursing and Bloomberg School of Public Health, 3400 North Charles

Street, Baltimore, MD 21218. 
Guarantor and corresponding author: Marcus K. Taylor, PhD, Naval Health Research Center, 140 Sylvester Road, San Diego, CA, 92106-3521. Phone: (619) 524-9859, fax: (619) 553-0677, e-mail: marcus.k.taylor2.civ@mail.mil

Report number 15-50, supported by the Office of Naval Research (Code 30), under Work Unit No. N1204. The views expressed in this article are those of the authors and do not necessarily reflect the official policy or position of the Department of the Navy, Department of Defense, or the U.S. Government. Approved for public release; distribution is unlimited. U.S. Government Work (17 USC 105). Not copyrighted in the U.S. This research has been conducted in compliance with all applicable federal regulations governing the protection of human subjects in research (Protocol NHRC.NHRC.2012.0006). Dr. Granger is founder and Chief Strategy and Senior Scientific Advisor at Salimetrics, LLC. His relationship with this entity is managed by the policies of the Conflict of Interest Committee at the Johns Hopkins University and the Office of Research Integrity and Assurance at Arizona State University. Dr. Taylor is Scientific Advisor for Sports and Performance at Salimetrics, LLC (Carlsbad, CA). His relationship with this entity is consistent with, and managed by, the policies of the Department of Defense, Naval Medical Research Center Office of Ethics, and the Naval Health Research Center Commanding Officer and Institutional Review Board.

Keywords: stress, anabolic, dehydroepiandrosterone, testosterone, military, special operations 


\begin{abstract}
We recently characterized the awakening responses and daily profiles of the catabolic stress hormone cortisol in elite military men. Anabolic hormones follow a similar daily pattern and may counteract the catabolic effects of cortisol. This companion report is the first to characterize daily profiles of anabolic hormones dehydroepiandrosterone (DHEA) and testosterone in this population. Overall, the men in this study displayed anabolic hormone profiles comparable to that of young, athletic populations. Consistent with the cortisol findings in our prior report, summary parameters of magnitude (hormone output) within the first hour after awakening displayed superior stability versus summary parameters of pattern for both DHEA ( $r$ range: 0.77-0.82) and testosterone ( $r$ range: $0.62-0.69)$. Summary parameters of evening function were stable for the two hormones (both $p<.001$ ), while the absolute decrease in testosterone across the day was a stable proxy of diurnal function $(p<.001)$. Removal of noncompliant subjects did not appreciably affect concentration estimates for either hormone at any time point, nor did it alter the repeatability of any summary parameter. The first of its kind, this report enables accurate estimations of anabolic balance and resultant effects upon health and human performance in this highly resilient yet chronically stressed population.
\end{abstract}




\section{INTRODUCTION}

We recently characterized awakening responses ${ }^{1}$ and daily patterns ${ }^{2}$ of the catabolic stress hormone cortisol in elite military men. Anabolic hormones (e.g., dehydroepiandrosterone $\left[\mathrm{DHEA}^{3,4}\right]$ and testosterone ${ }^{5-7}$ ) roughly follow the same daily pattern, loosely correlate to cortisol across the day, ${ }^{4}$ and appear to counteract cortisol's catabolic and neurodegenerative effects. ${ }^{8,9}$ Testosterone, and to a lesser extent anabolic precursors such as DHEA, promote muscle growth, strength, ${ }^{10}$ and other desired adaptations to resistance training. ${ }^{9}$ These hormones have individualized regulatory inputs, which may yield distinctions from cortisol in terms of magnitude and/or pattern of secretion across the day. ${ }^{4,11}$ The concurrent study of catabolic and anabolic hormone function in healthy subjects is valuable because it builds a comparative knowledge base from which to elucidate aberrant neuroendocrine function in clinical conditions $^{11}$ and also informs subclinical "allostatic load" models of chronic stress. ${ }^{12}$ These hormones are also routinely monitored to gauge training adaptations and optimize performance in competitive athletes. ${ }^{10,13}$

Although some work has documented acute anabolic hormone responses in military settings, ${ }^{14,15}$ no published research has established daily, free-living profiles of military members. This creates a critical knowledge gap, given that military members are a unique population with elevated risk of occupational stress, ${ }^{16}$ sleep disruption, ${ }^{17}$ trauma, ${ }^{18}$ and associated health consequences. ${ }^{19}$ Some anabolic hormones are known to counteract such risks. For instance, military deployment erodes free testosterone concentrations, ${ }^{15}$ while both endogenous ${ }^{14}$ and exogenous DHEA (a testosterone precursor) buffer stress profiles during military training, ${ }^{20}$ either through steroidogenic or independent neuroactive pathways. Likewise, sleep disruption-a pervasive military health challenge ${ }^{17}$ - is linked to reduced testosterone concentrations ${ }^{21}$ and 
compromised metabolic profiles, even in young men. ${ }^{22}$ Furthermore, anabolic hormone concentrations are tied to posttraumatic stress disorder, ${ }^{23,24}$ and preclinical evidence points to DHEA sulfate supplementation as a potential rehabilitative tool for traumatic brain injury. ${ }^{25}$ Clearly, precise characterization of anabolic hormone profiles in military members is a foundational step toward understanding and enhancing resilience in military members.

To date, some studies have characterized daily salivary DHEA patterns in diverse samples, including adolescents, ${ }^{3,11}$ athletes, ${ }^{26}$ college students, ${ }^{4}$ healthy adults, ${ }^{3,27,28}$ and older adults. ${ }^{29}$ Fusing these results, salivary DHEA concentrations appear highest in the morning, may or may not maintain waking values for up to 45 minutes, and then decline roughly $50 \%$ throughout the day en route to an evening nadir. Evolving consensus is that salivary DHEA reveals no dynamic increase (i.e., stimulatory burst) upon awakening, ${ }^{4,11,26,27}$ which is in sharp contrast to the typical awakening morphology of cortisol. ${ }^{30}$

Daily patterns of plasma and/or serum testosterone are relatively well-established in men of varied age groups, ${ }^{31}$ typically reflecting an observed peak at awakening following by a continuous decline across the day, and then reaching a nadir in the evening. In recent years, characterizations of salivary testosterone have also accumulated in athletic men, ${ }^{5-7}$ healthy nonathletes, ${ }^{32}$ and clinical populations. ${ }^{33}$ Shariat and colleagues, for example, documented daily salivary testosterone profiles in young, healthy male recreational weightlifters (mean age 18 years) assigned to a control (no exercise) condition, that showed peak values at 0600 (607.6 pmol/L; $165.6 \mathrm{pg} / \mathrm{mL})$ and an evening nadir at 2200 (323.2 pmol/L; 88.0 pg/mL). Similar magnitudes and patterns have been shown in young healthy men with resistance training experience. ${ }^{5,7}$ As with DHEA, testosterone does not appear to demonstrate a stimulatory burst upon awakening. ${ }^{5-7}$ 
The stability of salivary DHEA across repeated sampling days has not been extensively researched, but the available data are promising. In a study of healthy adolescent females, Oskis et al. ${ }^{11}$ showed that average morning salivary DHEA concentrations were very stable across 2 consecutive sampling days for both morning (i.e., average of waking and 30 minutes post waking; $r=0.83$ ) and a single evening sample (12 hours post waking; $r=0.66)$. Similarly, Hucklebridge et al. ${ }^{4}$ reported excellent stability for salivary DHEA across consecutive days for averaged morning values as well as averaged values across the day ( $r$ range $0.87-0.92)$, which were superior to that of salivary cortisol ( $r$ range $0.57-0.76)$.

Some studies also quantified the repeatability of daily salivary testosterone measurements ${ }^{7,32,34}$, and the findings are optimistic. Keevil et al. ${ }^{32}$ reported that a single salivary testosterone sample taken before 1000 in healthy men and women (irrespective of menstrual phase) did not differ when repeated across either 4 consecutive weeks or 4 consecutive months. Kraemer and colleagues ${ }^{7}$ evaluated testosterone concentrations at 17 data points across 2 consecutive sampling days in young athletic men, in both a rested condition and a condition that included an acute bout of resistance training. No intra-individual differences prevailed across the 2 days for either condition, with the exception of 0700 and 1700 in the rested condition.

Although important progress has been made linking poor sampling time compliance to distorted cortisol awakening responses, ${ }^{35}$ the effect of compliance on measurement of free-living DHEA or testosterone is extremely limited. One important exception is the work of Laudenslager and colleagues, ${ }^{27}$ which showed that the calculated slopes of diurnal decline in salivary DHEA of healthy men and women did not change appreciably upon exclusion of nonadherent subjects.

Despite this progress in diverse demographic sectors, remarkably little is known of the daily anabolic hormone profiles in military members. The present study was designed to (1) 
establish summary parameters of anabolic hormone (DHEA and testosterone) function in 58 elite military men, (2) evaluate the stability of summary parameters across 2 consecutive days of sampling, and (3) explore the effect of subject compliance with sampling times. As was shown with respect to cortisol in these men, ${ }^{1}$ we hypothesized that summary parameters of magnitude across the morning samples would reveal superior stability compared with summary parameters of pattern. In addition, we expected that summary parameters of daily hormone function (e.g., morning to evening slope) would demonstrate high stability. Furthermore, both summary parameters of magnitude and daily hormone function were expected to be robust to (i.e., show little distortion as a function of) noncompliance. Finally, unlike cortisol, no stimulatory burst of activity upon awakening was expected for either anabolic hormone.

\section{METHODS}

\section{Subjects}

Subjects were male active-duty military members of the elite Navy Sea, Air, and Land (SEAL) community, assigned to Naval Special Warfare Group ONE located in San Diego, California. No subjects were in a deployed status; rather, all were in a routine training status at their home station. Those who expressed an interest in participating attended an in-person meeting to review the details of the study and provide written informed consent. This protocol was approved by the Naval Health Research Center Institutional Review Board.

\section{Exclusion criteria and compliance instructions}

Exclusion criteria imposed for this study included smoking (smokeless tobacco use was permitted with strict compliance criteria), current diagnosis of type 1 diabetes or type 2 diabetes with prescribed medication, and self-reported use of anabolic substances within the past 3 
months. Compliance instructions were also provided. Specifically, subjects were asked to refrain from alcohol ingestion within $12 \mathrm{~h}$ of assessments, major meals, and smokeless tobacco product use within $1 \mathrm{~h}$ of assessments; ingestion of caffeine or dairy products within $30 \mathrm{~min}$ of assessments; and acidic or high-sugar foods/liquids or salivary stimulants (e.g., gum, lemon drops) within 10 min of each assessment.

\section{Salivary sampling protocol}

One salivary sample was taken five times per day for 2 days, for a total of 10 samples. The samples were self-collected by subjects in a free-living setting with oral swabs (Salimetrics, Carlsbad, CA). Each tube was labeled with the subject number, date, and expected time of sampling (e.g., WAKE+30). Subjects were also instructed to write the exact time of sampling on the label. In order to minimize social desirability bias, it was explained that this information was needed solely for scientific purposes. Samples were collected during the workweek (TuesdayWednesday or Wednesday-Thursday) and all participants were encouraged to engage in their typical daily routines.

Concise, standardized instructions for self-administration of samples were provided to each subject. On each day, subjects were instructed to collect samples immediately upon waking, $30 \mathrm{~min}$ after waking, and $60 \mathrm{~min}$ after waking, as well as $1600 \mathrm{~h}$ (midafternoon) and $2100 \mathrm{~h}$ (evening). Each subject was asked to rinse his mouth with water approximately 10 min prior to sample collection, to place all used oral swabs in a small cooler pre-packed with gel freezer packs (provided by study staff), and to place the entire cooler and contents in his home freezer each evening. Upon completion of the 2 days of salivary sampling, a member of the research staff arranged to pick up the small cooler and return it to a locked freezer at $-80^{\circ} \mathrm{C}$ until samples were shipped for processing. 


\section{Actigraphy}

The Motionlogger Actigraph (Ambulatory Monitoring, Ardsley, NY) was used to provide an objective indicator of wake time, which was compared against self-reported morning sampling times as a proxy of compliance. This protocol is detailed in Harris et al. ${ }^{17}$

\section{Determination of Salivary Analytes}

On the day of assay, all samples were thawed and centrifuged at 3,000 rpm for 15 minutes to remove mucins. Samples were assayed in duplicate for DHEA (test volume 50 ul; range of calibrators 10 to $1,000 \mathrm{pg} / \mathrm{mL}$; sensitivity $5 \mathrm{pg} / \mathrm{mL}$ ) and testosterone (test volume $25 \mathrm{ul}$; range of calibrators 6.1 to $600 \mathrm{pg} / \mathrm{mL}$; sensitivity $1 \mathrm{pg} / \mathrm{mL}$ ) using commercially available competitive immunoassays without modification to the manufacturer's recommended protocols (Salimetrics, Carlsbad, CA). Average intra- and inter-assay coefficients of variation for both assays were less than $10 \%$ and $15 \%$, respectively. Values used in statistical analyses were the average of duplicate assays for each sample.

\section{Data Reduction and Statistical Approach}

Consistent with our prior reports of cortisol in these men, ${ }^{1,2}$ summary parameters of magnitude and pattern after waking ${ }^{1}$ (following Fekedulegn et al. ${ }^{36}$ ) as well as summary parameters of evening and diurnal function ${ }^{2}$ were computed for DHEA and testosterone. Each parameter is described in Table I. Compliance with target sample times was also empirically assessed; this procedure is detailed in Taylor et al. ${ }^{1}$

Data were analyzed using SPSS statistical software, version 19.0 (IBM Corp., Armonk, NY). Distribution characteristics for all continuous variables were examined to determine if assumptions of normality were met, following conservative predefined limits (e.g., skewness between -1 and $1,{ }^{37}$ kurtosis between -3 and $3^{38}$ ). Variables exceeding any of these limits were 
transformed prior to performing the relevant statistical test. All data transformations reduced skewness and kurtosis to acceptable levels. Untransformed means are reported for ease of interpretation. Descriptive analyses were conducted to summarize subject characteristics. An analysis of variance with repeated measures evaluated changes in mean hormone concentrations across the day for each hormone. Greenhouse-Geisser corrections were implemented when sphericity assumptions were not met. Bonferroni-corrected post hoc paired samples $t$ tests explored time effects at each time point $(\mathrm{alpha}=.05 /$ four comparisons $=0.013)$. Bonferronicorrected paired samples $t$ tests also compared salivary hormone concentrations between day 1 and day 2 at each time point (alpha $=0.05 /$ five comparisons $=0.01)$. Stability across the 2 sampling days was then evaluated for each summary parameter via Pearson product-moment correlation analyses $(0.1=\text { small, } 0.3=\text { moderate, } 0.5=\text { high })^{39}$ and Cronbach's alpha $(\geq 0.7=$ good stability). ${ }^{40}$ Likewise, paired samples $t$ tests were used to evaluate whether the mean values

for each summary parameter differed across the 2 sampling days. Finally, to explore the effect of compliance on summary parameter stabilities, these analyses were repeated in respective morning-, evening-, and diurnal-compliant subgroups. All hypothesis tests were two-sided and the probability of committing a type I error was set at 0.05 .

\section{RESULTS}

\section{Subject characteristics}

Mean \pm SE age, body mass index (BMI), and years of military service for this sample were $33.4 \pm 1.0$ years, $27.5 \pm 0.3 \mathrm{~kg} / \mathrm{m}^{2}$, and $12.0 \pm 0.9$ years, respectively. Fourteen $(24.6 \%)$ were officers, four (7.0\%) were chief warrant officers, and 39 (68.4\%) were enlisted. Most were Caucasian (80.0\%). Seven (12.3\%) endorsed smokeless tobacco use, 18 (31.6\%) reported any 
type of nutritional supplement use, and a majority $(47 ; 82.5 \%)$ reported use of caffeine and/or energy drinks. Most (45; 78.9\%) had previously deployed for special operations missions.

Average DHEA concentrations were relatively stable from Wake to Wake +30 with a $58 \%$ decline from Wake to an observed nadir at $2100, F(2.4,106.7)=50.8, p<0.001, \eta_{\mathrm{p}}{ }^{2}=.53$, $1-\beta=1.0$. In Bonferroni-corrected post hoc comparisons, Wake +60 DHEA concentrations were strikingly lower than Wake, as were 1600 and 2100 (all $p<0.013$ ).

Daily DHEA concentrations at each sampling point for day 1 and day 2 are visualized in Figure 1. DHEA concentrations did not differ substantially at any given time point between day 1 and day 2 (all $p>0.01$ ). Stability of each DHEA summary parameter for all subjects is shown in Table II. Good stability for all three measures of magnitude were shown, with high strengths of association ( $r$ range: $0.77-0.82$, all $p<0.001)$ and Cronbach's alphas ranging from 0.85 to 0.92. Summary parameters of pattern did not demonstrate acceptable stability. The summary parameter of evening function was relatively stable. Although the constituent Wake and 2100 values were stable, neither absolute nor relative delta was a stable indicator of diurnal function. Effect of compliance on DHEA measurement is displayed in Table III. As shown, removal of noncompliant subjects did not appreciably alter DHEA concentration estimates at any time point (i.e., total sample means did not differ tellingly from the compliant subset). Beyond a subtle improvement in SP1, re-analysis of summary parameter stabilities in the compliant subgroup (Table IV) did not yield meaningful changes.

After an observed peak at Wake, average testosterone concentrations descended 55\% across the day from Wake, reaching an observed nadir at $2100, F(1.8,79.7)=108.0, p<0.001$, $\eta_{\mathrm{p}}{ }^{2}=.71,1-\beta=1.0$. In Bonferroni-corrected post hoc comparisons, Wake $+30, \mathrm{Wake}+60,1600$, and 2100 testosterone concentrations were markedly lower than Wake (all $p<0.013$ ). 
Daily testosterone concentrations at each sampling point for day 1 and day 2 are depicted in Figure 2. Testosterone concentrations did not differ substantively at any given time point between day 1 and day 2 (all $p>0.01$ ). Stability of each testosterone summary parameter for all subjects is shown in Table V. Good stability for all three measures of magnitude were shown $(r$ range: $0.62-0.69$, all $p<0.001$ ) and Cronbach's alphas ranging from 0.69 to 0.81 . Summary parameters of pattern did not demonstrate acceptable stability. The summary parameter of evening function was stable, as was absolute delta as a proxy of diurnal function. Effect of compliance on testosterone measurement is displayed in Table VI. As shown, removal of noncompliant subjects did not appreciably influence testosterone concentration estimates at any time point. Re-analysis of summary parameter stabilities in the compliant subgroups (Table VII) did not yield provocative changes in summary parameters of magnitude, evening function, or diurnal function. Noticeable improvements in summary parameters of pattern (specifically, absolute and relative reactivity) were achieved, although the observed $r$ and Cronbach's alpha were marginal.

\section{DISCUSSION}

This is the first study to comprehensively characterize daily anabolic hormone profiles of elite military men. This is a unique sample, inasmuch as elite military members may possess physiology that is distinguishable not only from the general population, but also from the general military population (either inherently, due to selection and/or specialized training, or some combination of these factors). Study participants displayed profiles comparable to that observed in young, athletic populations in other studies. It is most likely important for elite military members to maintain healthy and robust anabolic profiles, in light of the extreme occupational demands and chronic operational stress to which they are exposed. In this study, summary 
parameters of magnitude within the first hour after awakening displayed superior stability versus summary parameters of pattern for both hormones. Measures of evening function were also relatively stable for both hormones, while the absolute decrease in testosterone across the day was a stable proxy of diurnal function. Removal of noncompliant subjects did not appreciably affect measurement of either hormone.

DHEA concentrations were highest upon awakening, remained stable for 30 minutes, and then descended $58 \%$ across the day en route to an evening nadir. This overall pattern coincides with existing studies characterizing the DHEA profiles of demographically diverse samples. ${ }^{3,4,11,26-29}$ However, the average morning DHEA concentrations in these men was 40$50 \%$ higher than that identified in studies of young, healthy college students ${ }^{4}$ and healthy adult men and women, ${ }^{28}$ respectively. Instead, despite an average age of 33 years, morning concentrations in these men resembled that of younger athletes ${ }^{26}$ at an age where DHEA concentrations are expected to peak (approximately 20 years). ${ }^{41}$ Beyond the subtle, nonsignificant differences across the 2 sampling days at awakening and 30 minutes later, there was no evidence of an awakening stimulatory burst of DHEA activity. This mirrors other studies in diverse populations, ${ }^{4,11,26}$ and also strengthens the argument that DHEA and cortisol have differential regulatory input. That is, although they have proximal points of origin within the adrenal cortex (zona reticularis for DHEA ${ }^{42}$ and zona fasciculata for $\operatorname{cortisol}^{30}$ ) and share adrenocorticotropic hormone as a common secretagogue, ${ }^{11}$ cortisol appears to be further governed by an extra-pituitary pathway, most likely via the hypothalamic suprachiasmatic nucleus. $^{30}$

Salivary testosterone concentrations peaked at awakening, descended $56 \%$ across the day, and then reached an evening nadir. This general pattern is consistent with the extant literature in 
diverse samples of athletes, ${ }^{5-7}$ healthy nonathletes, ${ }^{32}$ and clinical populations. ${ }^{33}$ At an average age of 33 years, however, salivary testosterone concentrations of these men exceeded that of young, healthy male recreational weightlifters (mean age 18 years), ${ }^{6}$ as well as male university students (mean age 24 years) with resistance training experience. ${ }^{5}$ We observed a nearly identical magnitude and pattern of salivary testosterone as that observed by Kraemer et al. ${ }^{7}$ in young, healthy, recreationally weight-trained men (mean age 22 years). As with DHEA, testosterone did not display a stimulatory burst upon awakening, which is also consistent with current literature. ${ }^{5-}$ ${ }^{7}$ Testosterone is primarily synthesized in the testes, but it is also produced in the zona reticularis of the adrenal gland (collocated with the site of DHEA production) ${ }^{9}$ as well as the ovaries. ${ }^{9}$ This likely contributes to the observed morphology that resembles DHEA, yet is distinguishable from cortisol.

All three summary parameters of magnitude demonstrated superior stability in the total sample compared with summary parameters of pattern for both DHEA and testosterone. This is consistent with our prior comparison of magnitude and pattern estimates of cortisol in these same men. ${ }^{1,2}$ The stable parameters of magnitude in DHEA and testosterone are also very consistent with the broader literature. ${ }^{4,7,11,34}$ Additionally, removal of noncompliant subjects did not appreciably affect measurement of either hormone. As noted earlier, there is very little literature on this topic. One study ${ }^{27}$ evaluated the slopes of diurnal decline of salivary DHEA, concluding that nonadherence does not considerably influence this parameter estimate. As acknowledged in our prior report, ${ }^{1}$ effects of noncompliance may have been buffered by the adequate sample size and/or the relatively few noncompliant subjects overall. Integrating all of these findings, the summary parameters of magnitude for salivary DHEA and testosterone are quite stable across repeated sampling days, typically outperforming cortisol in this regard. Not only are the 
summary parameters of magnitude exceedingly more stable than their respective summary parameters of pattern, but they also appear to be less vulnerable to noncompliance.

Limitations of this study are recognized in prior reports. ${ }^{1,2}$ Most notably, we were unable to include an internal control group. With this in mind, comparison to hormone concentrations observed in other studies is muddled by differing conditions and methodologies. Such comparisons, then, must be interpreted cautiously. More useful comparison groups may include resistance-trained men of similar ages and/or age-matched members of other military communities. Our lab is currently evaluating the latter, with replicated methodology and similar environmental conditions (i.e., free-living, non-deployed). Also, subjects self-administered the salivary samples during free-living and were not under direct oversight by the research team. This leaves the precision of self-reported sampling times unverified, for which use of electronic tracking devices or similar technology ${ }^{27,43}$ could be useful. This advancement is under way in our lab. As with most free-living studies, these subjects also could not be monitored for other aspects of compliance (i.e., caffeine abstention proximal to sampling times), and substantial betweensubject variability in daily activities (including exercise) is certainly plausible.

The first of its kind, this study evolves our foundational research on cortisol awakening response in the elite military population. As a group, the men in this study displayed uncompromised anabolic hormone profiles comparable to that observed in other studies of young, athletic populations. These findings enable accurate estimations of anabolic balance, interrelationships of anabolic and catabolic function (including temporal trends), and the resultant effects upon health and human performance in unique military populations. Such is the focus of our forthcoming research. 


\section{REFERENCES}

1. Taylor MK, Sargent P, Hernández LM, Fuller SA, Padilla GA, Harris ER: Cortisol awakening response in elite military men: establishment of summary parameters and stability of repeated sampling. Med Sci Sports Exerc 2015; 47(5S).

2. Hernández LM, Fuller SA, Sargent P, Padilla GA, Harris ER, Taylor MK: Cortisol awakening response in elite military men: demographic and biobehavioral correlates. Med Sci Sports Exerc 2015; 47(5S).

3. Granger DA, Schwartz EB, Booth A, Curran M, Zakaria D: Assessing dehydroepiandrosterone in saliva: a simple radioimmunoassay for use in studies of children, adolescents and adults. Psychoneuroendocrinology 1999; 24(5): 567-79.

4. Hucklebridge F, Hussain T, Evans P, Clow A: The diurnal patterns of the adrenal steroids cortisol and dehydroepiandrosterone (DHEA) in relation to awakening. Psychoneuroendocrinology 2005; 30(1): 51-7.

5. Teo W, McGuigan MR, Newton MJ: The effects of circadian rhythmicity of salivary cortisol and testosterone on maximal isometric force, maximal dynamic force, and power output. J Strength Cond Res 2011; 25(6): 1538-45.

6. Shariat A, Kargarfard M, Danaee M, Bahri M, Tamrin S: Intensive resistance exercise and circadian salivary testosterone concentrations among young male recreational lifters. J Strength Cond Res 2015; 29(1): 151-8.

7. Kraemer WJ, Loebel CC, Volek JS, Ratamess NA, Newton RU, Wickham RB, Gotshalk LA, Duncan ND, Mazzetti SA, Gómez AL, Rubin MR, Nindl BC, Häkkinen K: The effect of heavy resistance exercise on the circadian rhythm of salivary testosterone in men. Eur J Appl Physiol 2001; 84(1-2): 13-8. 
8. Lazaridis I, Charalampopoulos I, Alexaki VI, Avlonitis N, Pediaditakis I, Efstathopoulos P, Calogeropoulou T, Castanas E, Gravanis A: Neurosteroid dehydroepiandrosterone interacts with nerve growth factor (NGF) receptors, preventing neuronal apoptosis. PLoS Biol 2011; 9(4): e1001051.

9. Vingren JL, Kraemer WJ, Ratamess NA, Anderson JM, Volek JS, Maresh CM: Testosterone physiology in resistance exercise and training: the up-stream regulatory elements. Sports Med 2010; 40(12): 1037-53.

10. Beaven CM, Cook CJ, Gill ND: Significant strength gains observed in rugby players after specific resistance exercise protocols based on individual salivary testosterone responses. J Strength Cond Res 2008; 22(2): 419-25.

11. Oskis A, Clow A, Thorn L, Loveday C, Hucklebridge F: Differences between diurnal patterns of salivary cortisol and dehydroepiandrosterone in healthy female adolescents. Stress $2012 ; 15(1): 110-4$.

12. Peters A, McEwen BS: Stress habituation, body shape and cardiovascular mortality. Neurosci Biobehav Rev 2015; 56: 139-150.

13. Gaviglio CM, Crewther BT, Kilduff LP, Stokes KA, Cook CJ: Relationship between pregame concentrations of free testosterone and outcome in rugby union. Int J Sports Physiol Perform 2014; 9(2): 324-31.

14. Morgan CA III, Rasmusson A, Pietrzak RH, Coric V, Southwick SM: Relationships among plasma dehydroepiandrosterone and dehydroepiandrosterone sulfate, cortisol, symptoms of dissociation, and objective performance in humans exposed to underwater navigation stress. Biol Psychiatry 2009; 66(4): 334-40. 
15. Hill NE, Woods DR, Delves SK, Murphy KG, Davison AS, Brett SJ, Quinton R, Turner S, Stacey M, Allsopp AJ, Fallowfield JL: The gonadotrophic response of Royal Marines during an operational deployment in Afghanistan. Andrology 2015; 3(2): 293-7.

16. Kessler RC, Stein MB, Bliese PD, Bromet EJ, Chiu WT, Cox KL, Colpe LJ, Fullerton CS, Gilman SE, Gruber MJ, Heeringa SG, Lewandowski-Romps L, Millikan-Bell A, Naifeh JA, Nock MK, Petukhova MV, Rosellini AJ, Sampson NA, Schoenbaum M, Zaslavsky AM, Ursano RJ: Occupational differences in US Army suicide rates. Psychol Med 2015; 20: 1-12 [Epub ahead of print].

17. Harris E, Taylor MK, Drummond SP, Larson GE, Potterat EG: Assessment of sleep disruption and sleep quality in Naval Special Warfare Operators. Mil Med 2015; 180(7): $803-8$.

18. Olivera A, Lejbman N, Jeromin A, French LM, Kim HS, Cashion A, Mysliwiec V, DiazArrastia R, Gill J: Peripheral total tau in military personnel who sustain traumatic brain injuries during deployment. JAMA Neurol 2015 [Epub ahead of print].

19. Smith BN, Tyzik AL, Neylan TC, Cohen BE: PTSD and obesity in younger and older veterans: results from the mind your heart study. Psychiatry Res 2015 [Epub ahead of print].

20. Taylor MK, Padilla GA, Stanfill KE, Markham AE, Khosravi JY, Ward MD, Koehler MM: Effects of dehydroepiandrosterone supplementation during stressful military training: a randomized, controlled, double-blind field study. Stress 2012;15(1): 85-96.

21. Leproult R, Van Cauter E: Effect of 1 week of sleep restriction on testosterone levels in young healthy men. JAMA 2011;305(21): 2173-4.

22. Reynolds AC, Dorrian J, Liu PY, Van Dongen HP, Wittert GA, Harmer LJ, Banks S: 
Impact of five nights of sleep restriction on glucose metabolism, leptin and testosterone in young adult men. PLoS One 2012; 7(7): e41218.

23. Usta MB, Tuncel OK, Akbas S, Aydin B, Say GN: Decreased dehydroepiandrosterone sulphate levels in adolescents with post-traumatic stress disorder after single sexual trauma. Nord J Psychiatry 2015; 15: 1-5 [Epub ahead of print].

24. Reijnen A, Geuze E, Vermetten E: The effect of deployment to a combat zone on testosterone levels and the association with the development of posttraumatic stress symptoms: a longitudinal prospective Dutch military cohort study.

Psychoneuroendocrinology 2015; 51: 525-33.

25. Milman A, Zohar O, Maayan R, Weizman R, Pick CG: DHEAS repeated treatment improves cognitive and behavioral deficits after mild traumatic brain injury. Eur Neuropsychopharmacol 2008; 18(3): 181-7.

26. Labsy Z, Prieur F, Le Panse B, Do MC, Gagey O, Lasne F, Collomp K: The diurnal patterns of cortisol and dehydroepiandrosterone in relation to intense aerobic exercise in recreationally trained soccer players. Stress 2013; 16(2): 261-5.

27. Laudenslager ML, Calderone J, Philips S, Natvig C, Carlson, NE: Diurnal patterns of salivary cortisol and DHEA using a novel collection device: electronic monitoring confirms accurate recording of collection time using this device. Psychoneuroendocrinology 2013; 38: 1596-606.

28. Ahn RS, Lee YJ, Choi JY, Kwon HB, Chun SI: Salivary cortisol and DHEA levels in the Korean population: age-related differences, diurnal rhythm, and correlations with serum levels. Yonsei Med J 2007; 48(3): 379-88. 
29. Wilcox RR, Granger DA, Szanton S, Clark F: Diurnal patterns and associations among salivary cortisol, DHEA and alpha-amylase in older adults. Physiol Behav 2014; 129: 11-6.

30. Clow A, Hucklebridge F, Stalder T, Evans P, Thorn L: The cortisol awakening response: more than a measure of HPA axis function. Neurosci Biobehav Rev 2010; 35: 97-103.

31. Brambilla DJ, Matsumoto AM, Araujo AB, McKinlay JB: The effect of diurnal variation on clinical measurement of serum testosterone and other sex hormone levels in men. J Clin Endocrinol Metab 2009;94(3): 907-13.

32. Keevil BG, MacDonald P, Macdowall W, Lee DM, Wu FC, NATSAL Team: Salivary testosterone measurement by liquid chromatography tandem mass spectrometry in adult males and females. Ann Clin Biochem 2014; 51: 368-78.

33. Smeets-Janssen MM, Roelofs K, van Pelt J, Spinhoven P, Zitman FG, Penninx BW, Giltay EJ: Salivary testosterone is consistently and positively associated with extraversion: results from The Netherlands Study of Depression and Anxiety. Neuropsychobiology 2015; 71(2): 76-84.

34. Liening SH, Stanton SJ, Saini EK, Schultheiss OC: Salivary testosterone, cortisol, and progesterone: two-week stability, interhormone correlations, and effects of time of day, menstrual cycle, and oral contraceptive use on steroid hormone levels. Physiol Behav 2010; 99(1): 8-16.

35. Hill Golden S, Sánchez BN, Desantis AS, Wu M, Castro C, Seeman TE, Tadros S, Shrager S, Diez Roux AV: Salivary cortisol protocol adherence and reliability by socio-demographic features: the Multi-Ethnic Study of Atherosclerosis. Psychoneuroendocrinology 2014; 43: $30-40$. 
36. Fekedulegn DB, Andrew ME, Burchfiel CM, Violanti JM, Hartley TA, Charles LE, Miller DB: Area under the curve and other summary indicators of repeated waking cortisol measurements. Psychosom Med 2007; 69: 651-9.

37. Leech LL, Barrett, KC, Morgan GA: SPSS for Intermediate Statistics: Use and Interpretation, 2nd ed. Lawrence Erlbaum Associates, Mahwah, NJ, 2005.

38. Taylor MK, Stone M, Laurent HK, Rauh, MJ, Granger DA: Neuroprotective-neurotrophic effect of endogenous dehydroepiandrosterone sulfate during intense stress exposure. Steroids 2014; 87: 54-8.

39. Cohen, J: Statistical Power Analysis for the Behavioral Sciences, 2nd ed. Erlbaum, Hillsdale, NJ, 1988.

40. Cronbach LJ: Coefficient alpha and the internal structure of tests. Psychometrika 1951; 16: $297-334$.

41. Maninger N, Wolkowitz OM, Reus VI, Epel ES, Mellon SH: Neurobiological and neuropsychiatric effects of dehydroepiandrosterone (DHEA) and dehydroepiandrosterone sulfate (DHEAS). Front Neuroendocrinol 2009; 30: 65-91.

42. Bird IM. In the zone: understanding zona reticularis function and its transformation by adrenarche. J Endocrinol 2012; 214(2): 109-11.

43. Kudielka BM, Broderick, JE, Kirschbaum C: Compliance with saliva sampling protocols: electronic monitoring reveals invalid cortisol daytime profiles in noncompliant subjects. Psychosom Med 2003; 65: 313-9. 
TABLE I. Summary Parameters

\begin{tabular}{|c|c|c|}
\hline Summary Parameter & General Definition & Operational Definition \\
\hline \multicolumn{3}{|l|}{ Measures of magnitude } \\
\hline Peak (pg/mL) & $\begin{array}{l}\text { Peak concentration at any of the three wake-dependent } \\
\text { measurements }\end{array}$ & $\begin{array}{l}\text { Greatest value of (Wake), } \\
(\text { Wake+30), and (Wake+60) }\end{array}$ \\
\hline $\mathrm{AUC}_{\mathrm{G}}$ & $\begin{array}{l}\text { Total area under the curve of all measurements. Accounts } \\
\text { for the distance between each measurement as well as the } \\
\text { distance of each measure from the ground (i.e., zero) }\end{array}$ & $\begin{array}{c}{[((\text { Wake }+ \text { Wake }+30) / 2) \times 30 \mathrm{~min}]+} \\
[((\text { Wake }+30)+(\text { Wake }+60)) / 2] \times 30 \mathrm{~min}]\end{array}$ \\
\hline Average (pg/mL) & Average of the three wake-dependent measurements & {$[$ Wake $+($ Wake+30) $+($ Wake+60) $] / 3$} \\
\hline \multicolumn{3}{|l|}{ Measures of pattern } \\
\hline $\mathrm{AUC}_{\mathrm{I}}$ & $\begin{array}{l}\text { Difference in area under and above the curve with respect } \\
\text { to baseline; compares the amount of increase (above the } \\
\text { baseline) versus amount of decrease (below the baseline) }\end{array}$ & $\begin{array}{c}\mathrm{AUC}_{\mathrm{G}}-\mathrm{AUC}_{\mathrm{B}} \\
\left(\mathrm{AUC}_{\mathrm{B}}=\mathrm{Wake} \times(30 \mathrm{~min}+30 \mathrm{~min})\right.\end{array}$ \\
\hline \multicolumn{3}{|l|}{ Reactivity } \\
\hline Absolute $(\mathrm{pg} / \mathrm{mL})$ & $\begin{array}{l}\text { Change in concentration from waking to } 30 \text { minutes after } \\
\text { waking }\end{array}$ & $($ Wake+30) $-($ Wake $)$ \\
\hline
\end{tabular}




\begin{tabular}{|c|c|c|}
\hline Relative $(\%)$ & $\begin{array}{l}\text { Change in concentration from waking to } 30 \text { minutes after } \\
\text { waking }\end{array}$ & {$[(($ Wake +30$)-($ Wake $)) /($ Wake $)] \times 100 \%$} \\
\hline $\mathrm{SP} 1(\mathrm{pg} / \mathrm{mL} / \mathrm{hr})$ & $\begin{array}{l}\text { Slope of the line through the baseline and last } \\
\text { measurement }\end{array}$ & {$[($ Wake +60$)-($ Wake $)] / 1 \mathrm{hr}$} \\
\hline \multicolumn{3}{|l|}{ Measure of evening function } \\
\hline Average & Average of the two afternoon/evening measurements. & $(1600+2100) / 2$ \\
\hline \multicolumn{3}{|l|}{ Measures of diurnal function } \\
\hline \multicolumn{3}{|l|}{ Delta } \\
\hline Absolute (pg/mL) & Change in concentration from waking to 2100 & $2100-$ Wake \\
\hline Relative (\%) & Change in concentration from waking to 2100 & {$[(2100-$ Wake $) /($ Wake $)] \times 100 \%$} \\
\hline
\end{tabular}


TABLE II. DHEA Summary Parameters and Stability of Repeated Sampling: Total Sample

\begin{tabular}{|c|c|c|c|c|c|c|c|c|}
\hline \multirow[t]{2}{*}{ Summary Parameter } & \multirow[t]{2}{*}{$N$} & \multirow{2}{*}{$\begin{array}{c}\text { Day } 1 \\
\mathrm{M} \pm \mathrm{SE}\end{array}$} & \multirow{2}{*}{$\begin{array}{c}\text { Day } 2 \\
\mathrm{M} \pm \mathrm{SE}\end{array}$} & \multirow[t]{2}{*}{$r$} & \multirow[t]{2}{*}{$p$} & \multirow[t]{2}{*}{$t$} & \multirow[t]{2}{*}{$p$} & \multirow[t]{2}{*}{$\alpha$} \\
\hline & & & & & & & & \\
\hline \multicolumn{9}{|l|}{ Measures of magnitude } \\
\hline Peak (pg/mL) & 55 & $368.8 \pm 33.4$ & $376.6 \pm 39.1$ & .81 & $<0.001$ & -0.4 & 0.69 & 0.92 \\
\hline $\mathrm{AUC}_{\mathrm{G}}$ & 52 & $17,305.0 \pm 1,301.2$ & $17,941.7 \pm 1,788.3$ & .77 & $<0.001$ & -0.6 & 0.57 & 0.85 \\
\hline Average $(\mathrm{pg} / \mathrm{mL})$ & 52 & $284.7 \pm 22.5$ & $292.1 \pm 27.9$ & .82 & $<0.001$ & -0.5 & 0.61 & 0.91 \\
\hline \multicolumn{9}{|l|}{ Measures of pattern } \\
\hline $\mathrm{AUC}_{\mathrm{I}}$ & 52 & $-2,114.9 \pm 1,187.8$ & $-2.9 \pm 1,374.4$ & -.04 & 0.80 & -1.0 & 0.30 & $a$ \\
\hline \multicolumn{9}{|l|}{ Reactivity } \\
\hline Absolute (pg/mL) & 54 & $-21.5 \pm 28.0$ & $16.0 \pm 31.8$ & -.22 & 0.12 & -0.8 & 0.46 & $a$ \\
\hline Relative (\%) & 54 & $9.2 \pm 7.3$ & $12.8 \pm 7.4$ & .05 & 0.69 & -0.4 & 0.72 & 0.16 \\
\hline $\mathrm{SP} 1(\mathrm{pg} / \mathrm{mL} / \mathrm{hr})$ & 52 & $-92.5 \pm 25.6$ & $-41.6 \pm 28.1$ & .29 & 0.04 & -1.5 & 0.14 & 0.35 \\
\hline \multicolumn{9}{|l|}{ Measure of evening function } \\
\hline Average (pg/mL) & 49 & $113.1 \pm 6.7$ & $135.4 \pm 21.7$ & .75 & $<0.001$ & -1.2 & 0.22 & 0.54 \\
\hline
\end{tabular}




\begin{tabular}{|c|c|c|c|c|c|c|c|c|}
\hline \multicolumn{9}{|l|}{ Measures of diurnal function } \\
\hline Wake & 55 & $316.7 \pm 32.5$ & $297.1 \pm 27.3$ & .73 & $<0.001$ & 0.9 & 0.39 & 0.84 \\
\hline 2100 & 53 & $104.8 \pm 6.4$ & $114.4 \pm 17.1$ & .68 & $<0.001$ & -0.7 & 0.49 & 0.61 \\
\hline \multicolumn{9}{|l|}{ Delta } \\
\hline Absolute $(\mathrm{pg} / \mathrm{mL})$ & 53 & $-213.0 \pm 30.6$ & $-181.6 \pm 24.6$ & .30 & 0.03 & -0.9 & 0.35 & 0.43 \\
\hline Relative (\%) & 53 & $-57.4 \pm 3.2$ & $-59.6 \pm 2.9$ & .20 & 0.15 & 0.5 & 0.60 & 0.28 \\
\hline
\end{tabular}

${ }^{a}$ Reliability model assumptions were violated due to negative average covariance across day 1 and day 2. 
TABLE III. Effect of Compliance With Salivary Sampling Times on DHEA Measurement at Each Time

\section{Point}

\begin{tabular}{|c|c|c|c|c|c|c|}
\hline & \multicolumn{2}{|c|}{ Compliant } & \multicolumn{2}{|r|}{ Noncompliant } & \multicolumn{2}{|r|}{ Total } \\
\hline & \multirow{2}{*}{$n$} & \multicolumn{2}{|l|}{$\mathrm{M} \pm \mathrm{SE}$} & \multicolumn{2}{|l|}{$\mathrm{M} \pm \mathrm{SE}$} & $\mathrm{M} \pm \mathrm{SE}$ \\
\hline & & DHEA $(\mathrm{pg} / \mathrm{mL})$ & $n$ & DHEA $(\mathrm{pg} / \mathrm{mL})$ & $n$ & DHEA (pg/mL) \\
\hline \multicolumn{7}{|l|}{ Day 1} \\
\hline Wake & 41 & $306.0 \pm 38.8$ & 5 & $360.3 \pm 113.4$ & 46 & $311.9 \pm 36.4$ \\
\hline Wake +30 & 40 & $275.1 \pm 21.3$ & 5 & $358.5 \pm 127.7$ & 45 & $284.3 \pm 23.2$ \\
\hline Wake + 60 & 36 & $235.2 \pm 28.7$ & 8 & $223.1 \pm 55.3$ & 44 & $233.0 \pm 25.3$ \\
\hline 1600 & 42 & $118.4 \pm 8.4$ & 4 & $119.7 \pm 14.9$ & 46 & $118.5 \pm 7.8$ \\
\hline 2100 & 41 & $102.1 \pm 6.6$ & 6 & $128.2 \pm 33.5$ & 47 & $105.4 \pm 7.1$ \\
\hline \multicolumn{7}{|l|}{ Day 2} \\
\hline Wake & 38 & $268.3 \pm 20.8$ & 7 & $324.5 \pm 106.4$ & 45 & $277.0 \pm 23.6$ \\
\hline Wake +30 & 39 & $309.8 \pm 47.3$ & 6 & $263.9 \pm 44.8$ & 45 & $303.7 \pm 41.4$ \\
\hline Wake +60 & 38 & $249.0 \pm 36.6$ & 6 & $186.4 \pm 31.7$ & 44 & $240.5 \pm 32.0$ \\
\hline
\end{tabular}


$142.1 \pm 28.9$

46

$156.7 \pm 27.2$

2100

44

$115.1 \pm 20.4$

160.9

45

$116.1 \pm 20.0$ 
TABLE IV. DHEA Summary Parameters and Stability of Repeated Sampling: Compliant Subjects ${ }^{a}$

\begin{tabular}{|c|c|c|c|c|c|c|c|c|}
\hline \multirow[t]{2}{*}{ Summary Parameter } & \multirow[t]{2}{*}{$N$} & \multirow{2}{*}{$\begin{array}{c}\text { Day } 1 \\
\mathrm{M} \pm \mathrm{SE}\end{array}$} & \multirow{2}{*}{$\begin{array}{c}\text { Day } 2 \\
\mathrm{M} \pm \mathrm{SE}\end{array}$} & \multirow[t]{2}{*}{$r$} & \multirow[t]{2}{*}{$p$} & \multirow[t]{2}{*}{$t$} & \multirow[t]{2}{*}{$p$} & \multirow[t]{2}{*}{$\alpha$} \\
\hline & & & & & & & & \\
\hline \multicolumn{9}{|l|}{ Measures of magnitude } \\
\hline Peak $(\mathrm{pg} / \mathrm{mL})$ & 28 & $323.2 \pm 32.5$ & $316.3 \pm 26.5$ & .75 & $<0.001$ & 0.3 & 0.76 & 0.84 \\
\hline $\mathrm{AUC}_{\mathrm{G}}$ & 25 & $15,874.9 \pm 1530.9$ & $15,900.8 \pm 1,402.1$ & .78 & $<0.001$ & -0.0 & 0.97 & 0.92 \\
\hline Average $(\mathrm{pg} / \mathrm{mL})$ & 25 & $262.2 \pm 25.1$ & $256.1 \pm 21.5$ & .80 & $<0.001$ & 0.5 & 0.64 & 0.92 \\
\hline \multicolumn{9}{|l|}{ Measures of pattern } \\
\hline $\mathrm{AUC}_{\mathrm{I}}$ & 25 & $-1,553.9 \pm 1,190.1$ & $1,116.9 \pm 1,109.2$ & .39 & 0.05 & -2.0 & 0.06 & 0.49 \\
\hline \multicolumn{9}{|l|}{ Reactivity } \\
\hline Absolute (pg/mL) & 27 & $-13.7 \pm 23.5$ & $34.1 \pm 25.3$ & .25 & 0.21 & -1.6 & 0.13 & 0.36 \\
\hline Relative (\%) & 27 & $3.6 \pm 6.9$ & $16.8 \pm 10.3$ & .04 & 0.84 & -1.1 & 0.28 & 0.12 \\
\hline $\mathrm{SP} 1(\mathrm{pg} / \mathrm{mL} / \mathrm{hr})$ & 25 & $-66.3 \pm 32.7$ & $-16.0 \pm 27.8$ & .46 & 0.02 & -1.5 & 0.14 & 0.58 \\
\hline \multicolumn{9}{|l|}{ Measure of evening function } \\
\hline Average (pg/mL) & 30 & $106.1 \pm 7.6$ & $108.1 \pm 8.6$ & .77 & $<0.001$ & -.4 & 0.72 & 0.87 \\
\hline
\end{tabular}




\section{Measures of diurnal function}

$\begin{array}{lcccccccc}\text { Wake } & 34 & 309.5 \pm 44.8 & 273.7 \pm 22.6 & .78 & <0.001 & 1.2 & 0.3 & 0.77 \\ 2100 & 37 & 101.7 \pm 6.6 & 94.1 \pm 8.1 & .68 & <0.001 & 1.3 & 0.22 & 0.80 \\ \text { Delta } & & & & & & & & \\ \text { Absolute }(\mathrm{pg} / \mathrm{mL}) & 27 & -145.2 \pm 21.0 & -160.8 \pm 16.9 & .37 & 0.06 & 0.7 & 0.47 & 0.54 \\ \quad \text { Relative }(\%) & 27 & -52.4 \pm 4.7 & -62.4 \pm 3.5 & .23 & 0.25 & 1.9 & 0.07 & 0.32\end{array}$

${ }^{a}$ Compliant subjects were categorized based on compliance across both days with the following: all three wake-dependent samples for measures of magnitude and pattern, both afternoon/evening samples for measure of evening function, and for both Wake and 2100 for absolute and relative delta. 
TABLE V. Testosterone Summary Parameters and Stability of Repeated Sampling: Total Sample

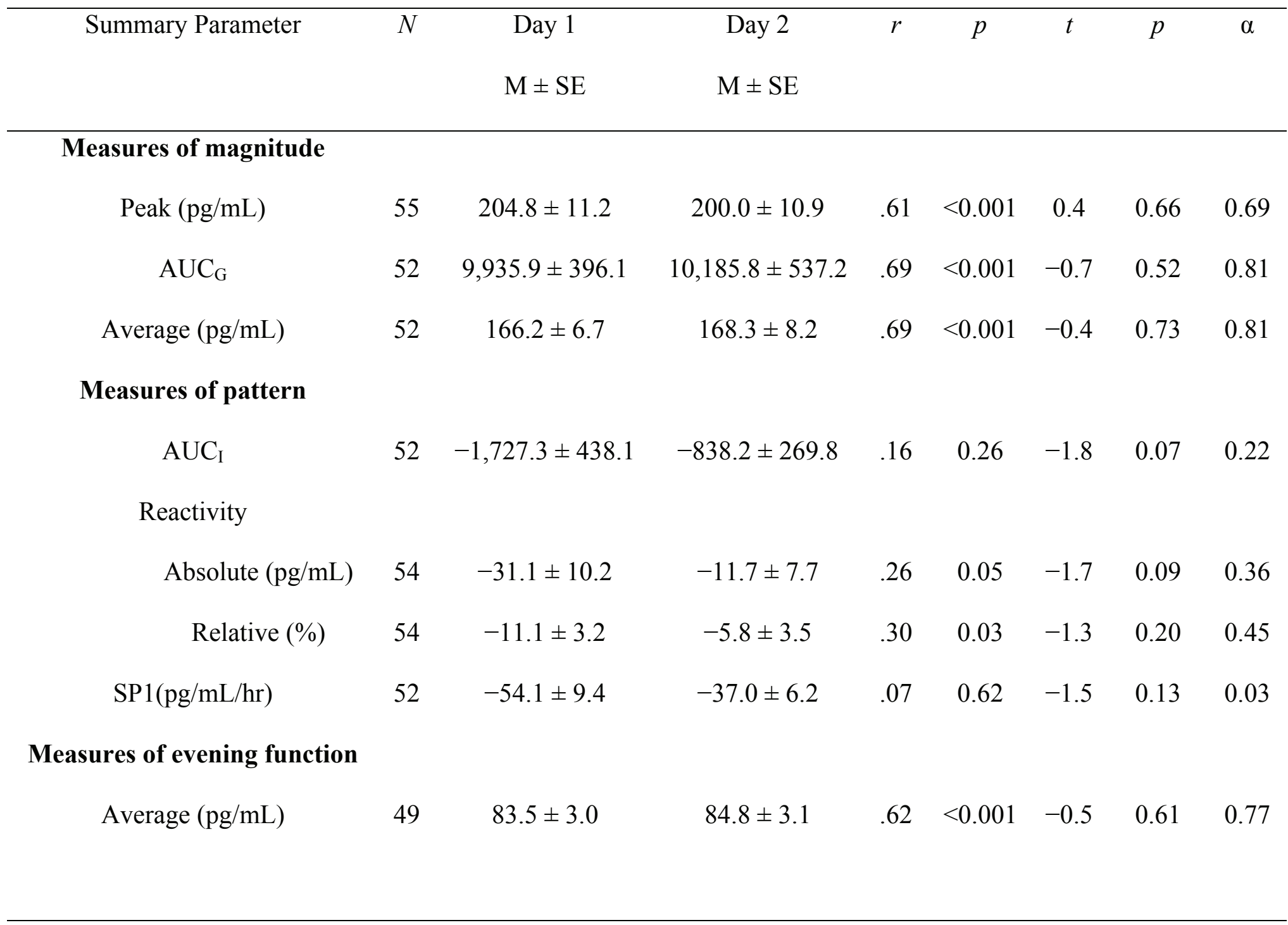




\begin{tabular}{lcccccccc}
\hline Measures of diurnal function & & & & & & & \\
Wake & 55 & $195.1 \pm 11.0$ & $186.4 \pm 8.8$ & .55 & $<0.001$ & 0.9 & 0.37 & 0.70 \\
2100 & 53 & $78.3 \pm 3.2$ & $79.5 \pm 3.8$ & .53 & $<0.001$ & -0.4 & 0.73 & 0.69 \\
Delta & & & & & & & & \\
Absolute (pg/mL) & 53 & $-107.8 \pm 6.8$ & $-105.3 \pm 9.0$ & .56 & $<0.001$ & -0.3 & 0.74 & 0.72 \\
$\quad$ Relative (\%) & 53 & $-55.8 \pm 2.0$ & $-53.9 \pm 2.7$ & .33 & 0.02 & -0.7 & 0.51 & 0.46 \\
\hline
\end{tabular}


TABLE VI. Effect of Compliance With Salivary Sampling Times on Testosterone Measurement at Each Time Point

\begin{tabular}{|c|c|c|c|c|c|c|}
\hline & \multicolumn{2}{|c|}{ Compliant } & \multicolumn{2}{|c|}{ Noncompliant } & \multicolumn{2}{|r|}{ Total } \\
\hline & \multirow{3}{*}{$n$} & $\mathrm{M} \pm \mathrm{SE}$ & \multicolumn{2}{|r|}{$\mathrm{M} \pm \mathrm{SE}$} & \multicolumn{2}{|r|}{$\mathrm{M} \pm \mathrm{SE}$} \\
\hline & & Testosterone & $n$ & Testosterone & $n$ & Testosterone \\
\hline & & $(\mathrm{pg} / \mathrm{mL})$ & & $(\mathrm{pg} / \mathrm{mL})$ & & $(\mathrm{pg} / \mathrm{mL})$ \\
\hline \multicolumn{7}{|l|}{ Day 1} \\
\hline Wake & 41 & $200.3 \pm 13.9$ & 5 & $178.1 \pm 31.8$ & 46 & $197.9 \pm 12.8$ \\
\hline Wake +30 & 40 & $164.3 \pm 8.8$ & 5 & $154.8 \pm 32.3$ & 45 & $163.2 \pm 8.4$ \\
\hline Wake +60 & 36 & $146.0 \pm 8.0$ & 8 & $130.3 \pm 17.8$ & 44 & $143.2 \pm 7.3$ \\
\hline 1600 & 42 & $87.0 \pm 3.9$ & 4 & $96.2 \pm 7.0$ & 46 & $87.8 \pm 3.7$ \\
\hline 2100 & 41 & $77.8 \pm 4.0$ & 6 & $82.8 \pm 9.2$ & 47 & $78.5 \pm 3.7$ \\
\hline \multicolumn{7}{|l|}{ Day 2} \\
\hline Wake & 38 & $194.7 \pm 11.3$ & 7 & $172.1 \pm 25.8$ & 45 & $191.2 \pm 10.3$ \\
\hline Wake +30 & 38 & $169.3 \pm 11.9$ & 6 & $223.2 \pm 71.2$ & 44 & $176.6 \pm 13.9$ \\
\hline Wake +60 & 38 & $154.6 \pm 8.6$ & 6 & $113.5 \pm 10.8$ & 44 & $149.0 \pm 7.8$ \\
\hline
\end{tabular}




\begin{tabular}{ccccccc}
\hline 1600 & 39 & $91.2 \pm 4.0$ & 7 & $98.9 \pm 8.4$ & 46 & $92.4 \pm 3.6$ \\
2100 & 44 & $77.0 \pm 4.3$ & 1 & 137.7 & 45 & $78.4 \pm 4.4$ \\
\hline
\end{tabular}


TABLED VII. Testosterone Summary Parameters and Stability of Repeated Sampling: Compliant Subjects ${ }^{a}$

\begin{tabular}{|c|c|c|c|c|c|c|c|c|}
\hline \multirow[t]{2}{*}{ Summary Parameter } & \multirow[t]{2}{*}{$N$} & \multirow{2}{*}{$\begin{array}{c}\text { Day } 1 \\
\mathrm{M} \pm \mathrm{SE}\end{array}$} & \multirow{2}{*}{$\begin{array}{c}\text { Day } 2 \\
\mathrm{M} \pm \mathrm{SE}\end{array}$} & \multirow[t]{2}{*}{$r$} & \multirow[t]{2}{*}{$p$} & \multirow[t]{2}{*}{$t$} & \multirow[t]{2}{*}{$p$} & \multirow[t]{2}{*}{$\alpha$} \\
\hline & & & & & & & & \\
\hline \multicolumn{9}{|l|}{ Measures of magnitude } \\
\hline Peak (pg/mL) & 28 & $221.1 \pm 19.3$ & $217.6 \pm 14.3$ & .75 & $<0.001$ & 0.2 & 0.83 & 0.84 \\
\hline $\mathrm{AUC}_{\mathrm{G}}$ & 25 & $10,288.6 \pm 615.3$ & $10,994.7 \pm 758.5$ & .80 & $<0.001$ & -1.5 & 0.15 & 0.87 \\
\hline Average $(\mathrm{pg} / \mathrm{mL})$ & 25 & $173.2 \pm 10.4$ & $182.7 \pm 11.9$ & .76 & $<0.001$ & -1.1 & 0.27 & 0.84 \\
\hline \multicolumn{9}{|l|}{ Measures of pattern } \\
\hline $\mathrm{AUC}_{\mathrm{I}}$ & 25 & $-2,476.5 \pm 822.3$ & $-1,135.5 \pm 418.2$ & .25 & 0.23 & -1.6 & 0.13 & 0.26 \\
\hline \multicolumn{9}{|l|}{ Reactivity } \\
\hline Absolute $(\mathrm{pg} / \mathrm{mL})$ & 27 & $-46.5 \pm 18.4$ & $-21.1 \pm 10.4$ & .50 & 0.01 & -1.4 & 0.16 & 0.47 \\
\hline Relative (\%) & 27 & $-15.9 \pm 4.6$ & $-7.1 \pm 5.3$ & .40 & 0.04 & -1.6 & 0.12 & 0.57 \\
\hline $\mathrm{SP} 1(\mathrm{pg} / \mathrm{mL} / \mathrm{hr})$ & 25 & $-80.0 \pm 17.4$ & $-41.4 \pm 11.0$ & .02 & 0.95 & -1.5 & 0.16 & $b$ \\
\hline \multicolumn{9}{|l|}{ Measures of evening function } \\
\hline Average $(\mathrm{pg} / \mathrm{mL})$ & 30 & $82.7 \pm 4.2$ & $82.5 \pm 4.1$ & .65 & $<0.001$ & .03 & 0.98 & 0.79 \\
\hline
\end{tabular}




\begin{tabular}{lcccccccc}
\hline Measures of diurnal function & & & & & & & \\
Wake & 34 & $203.9 \pm 16.3$ & $200.8 \pm 12.2$ & .50 & 0.01 & 0.2 & 0.83 & 0.65 \\
2100 & 37 & $77.9 \pm 4.3$ & $77.3 \pm 4.6$ & .56 & $<0.001$ & 0.2 & 0.88 & 0.72 \\
Delta & & & & & & & & \\
Absolute $(\mathrm{pg} / \mathrm{mL})$ & 27 & $-106.7 \pm 9.7$ & $-111.5 \pm 11.1$ & .51 & 0.01 & 0.5 & 0.64 & 0.69 \\
$\quad$ Relative (\%) & 27 & $-55.6 \pm 2.9$ & $-56.5 \pm 3.9$ & .14 & 0.49 & 0.2 & 0.85 & 0.21
\end{tabular}

${ }^{a}$ Compliant subjects were categorized based on compliance across both days with the following: all three wake-

dependent samples for measures of magnitude and pattern, both afternoon/evening samples for measure of evening

function, and for both Wake and 2100 for absolute and relative delta.

${ }^{b}$ Reliability model assumptions were violated due to negative average covariance across day 1 and day 2. 
FIGURE1. Daily DHEA profile of total sample, day 1 versus day 2.

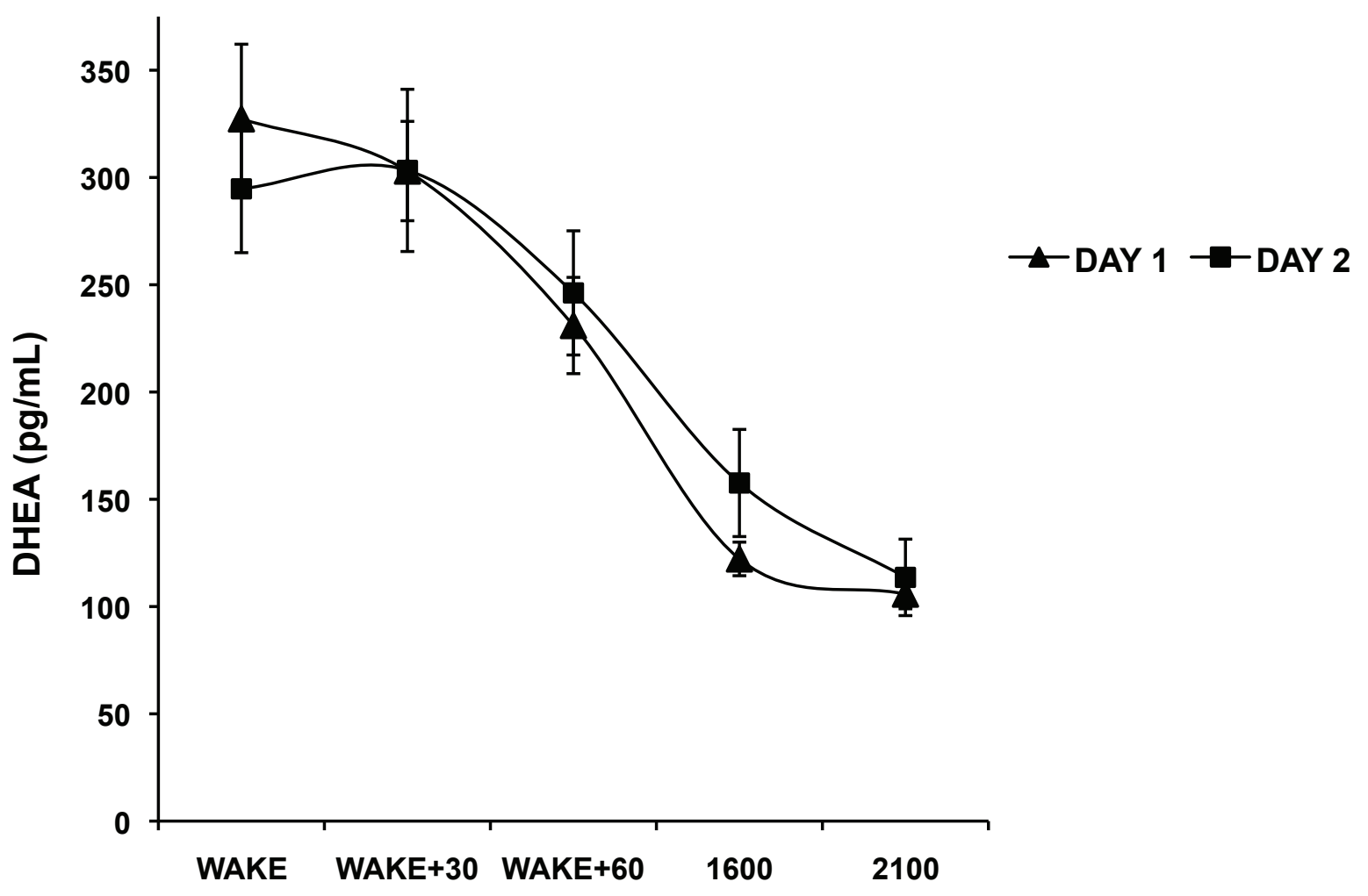


FIGURE 2. Daily testosterone profile of total sample, day 1 versus day 2.

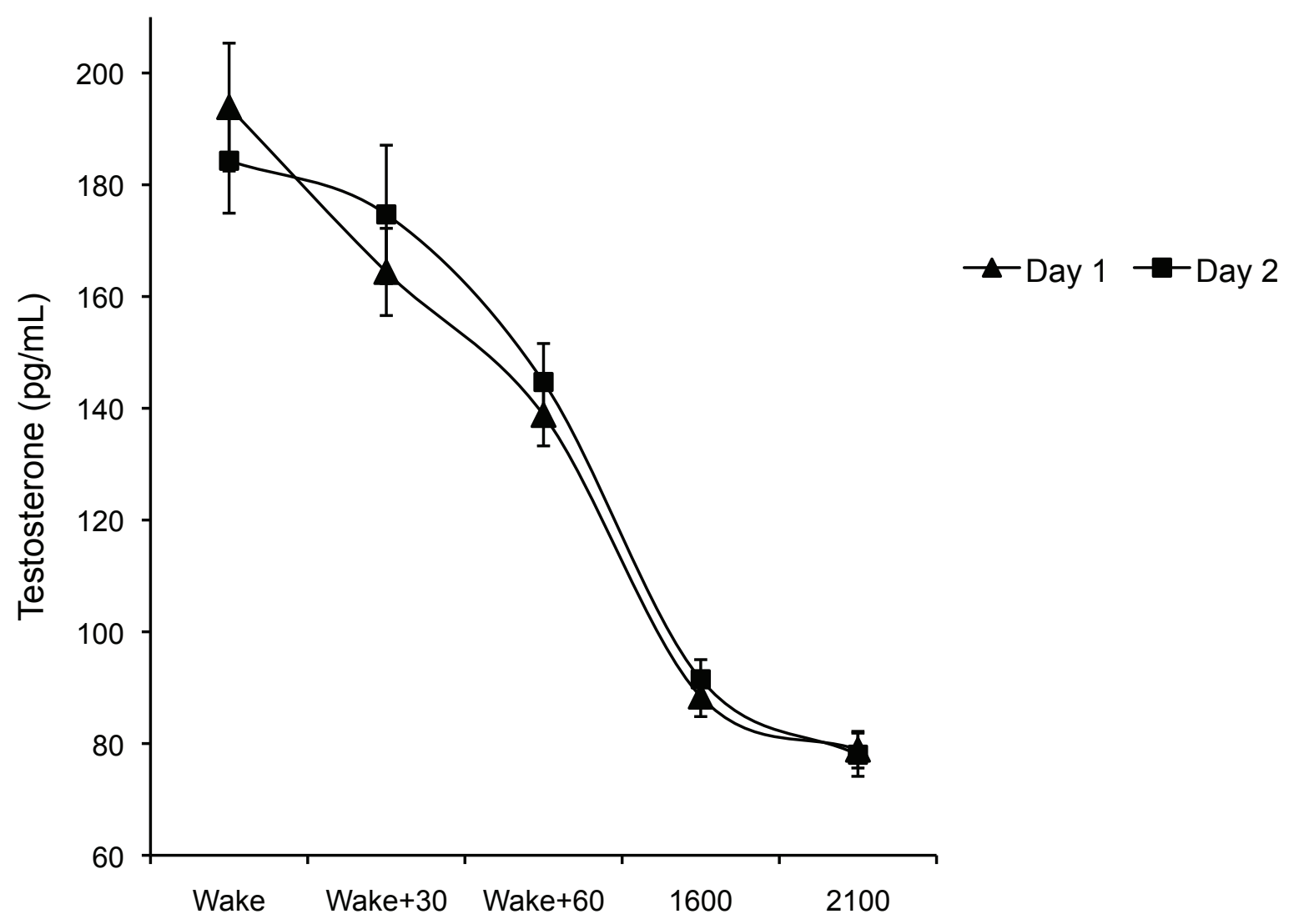

